\title{
Book Preservation Boxes
}

\author{
Alan Keely
}

During the past fifteen years librarians have become increasingly aware of the deterioration of books under their care. A number of ways of remedying this problem have been adopted. These include rebinding, microforming, replacement, or restoration. There are occasions however, when the original book should be kept but not altered, either because of the book's intrinsic value or because money is not available to restore it. In these cases, some librarians have resorted to putting the book in a protective container, or book box, and placing it back on the shelf.

Although book boxes have been used for over two centuries, very little published information is available about them beyond a few bits and pieces of information in books on bookbinding and preservation, and a few journal articles scattered throughout the library literature. Several questions come to mind as the idea of using book boxes is explored. For instance, what are the different types of book boxes? How do librarians find out which type of box is best suited for a particular book? And how does a librarian go about deciding which box is the best to use? As we shall see, boxes can be quite practical and an economical means of preservation.

Because appearance is strictly a matter of aesthetic judgment on the part of the librarian, decoration of book boxes will not be discussed unless it affects their design and/or usability.

\section{Why Boxes?}

Book boxes have been around for quite some time. They have been, and probably still are, most often thought of as something to enhance the appearance of prestigious books, not as something that will help preserve them. It has only recently been established that if a book can be protected against harmful agents common to most libraries (such as sunlight, fluctuations in temperature and humidity, and mechanical damage), it will last considerably longer than if it went unprotected. By controlling these factors in areas

Alan Keely is Instructor/Cataloger at Lupton Library, University of Tennessee at Chattanooga, Chattanooga, TN 37403. where books are stored and by using book boxes where needed, librarians can avoid these enemies of books and prevent much unnecessary damage to their collections.

It is important to remember that book boxes will not completely halt the deterioration of book paper, but they will add many years to its life. On the other hand, book boxes will eliminate most, if not all mechanical damage, depending on the type of box chosen. For badly deteriorated books, they can provide enough protection until such time as more extensive preservation treatment can be undertaken.

\section{What Constitutes A Good Book Box?}

A good book box, regardless of its design, must be made of durable, high quality materials. The most commonly used are binders boards, felt (for lining the boxes), ribbon (used for the pulls), string (used for ties), different kinds of book cloth or buckram as covering materials, and adhesives to hold the box together.

In her book, Design and Construction of Boxes for the Protection of Rare Books, Margaret Brown lists specific qualities of materials and sources of supply that she recommends for use in making boxes. ${ }^{1}$

In general, Brown recommends that binders boards be either $100 \%$ rag board or $100 \%$ chemical wood fiber mat board. ${ }^{2}$ Although any neutral $\mathrm{pH}$ or alkaline board that is durable may be used, it is important that boards and all paper used have enough of an alkaline reserve to act as a buffer against acid migration. It is also important to use a board that is flexible enough to be folded and creased without splitting.

The extraction $\mathrm{pH}$ of felts should not be less than $6.5 .^{3}$ Ribbon and string used for pulls and ties should be acid-free. String should be strong enough so that it will not fray after repeated use. Of the library buckrams available, starch-filled buckrams provide the flexibility necessary for the covering of the boxes. The dyes used should be non-fugitive under high relative humidities. As an adhesive, an internally plasticized polyvinyl acetate aqueous emulsion is recommended. These 
adhesives are not likely to dry out and become brittle as are most common adhesives.

Samples of all materials should be tested to see if $\mathrm{pH}$ levels conform to established standards. Most materials may be tested for their acidity quite easily using a simple kit which is readily available.

From the descriptions of various boxes mentioned in the literature a good book box should have the following characteristics. First, the box should place the book under light but firm pressure, preventing distortion of the covers and textblock, expansion, or shifts of the book's position should the box be dropped or stored in an otherwise less than satisfactory manner. ${ }^{4}$

Second, the box should eliminate abrasion to the book from shelf surfaces, supports, and other books. It should also protect the headcap from damage by patrons who like to hook their finger over the headcap and pull to remove a book from the shelf.

Third, a good book box should protect its contents from the harmful effects of the environment including:

1. light which can fade the binding and cause deterioration of the textblock.

2. dust and other airborne particulates which may carry harmful chemicals that can react with the cover materials and cause damage.

3. fluctuations in temperature and humidity.

Some conservators recommend that seldom used books be sealed in thin mylar envelopes, providing an airtight environment to further protect them. ${ }^{5}$ Others feel that an air-tight seal is of "dubious" value. ${ }^{6}$ The choice to use the mylar envelopes should be made in light of how much use the book is expected to receive.

Fourth, the box should also eliminate the possibility of damage that could be caused by rodents and other vermin that may occasionally infest a library.

Fifth, in terms of usability, a closed box should indicate to the user, by its design and decoration, how the box is to be shelved. ${ }^{7}$ The box should also indicate that the user should refrain from opening the book while it is still in the box. Regardless of the kind of box, as a rule the user should place the box on a table and gently and carefully remove the book before using. In this way, both book and box are protected from damage. The box should always indicate that care be exercised when handling the book.

Finally, upon opening the box, the user should immediately be able to ascertain the condition of the book. If, for example, the covers of the book are detached from the textblock, the box should have a separate portfolio and portfolio slot for the detached pieces as part of the design, so the user immediately realizes the book is in less than perfect condition and extreme care should be exercised in handling.

\section{Selecting A Box Design}

Before deciding on a box for a particular book, the librarian must ascertain the material as well as the physical characteristics of the book. Material characteristics include the type of material used for the textblock and the binding; supplementary materials, such as maps, foldouts, prints or engravings, and other documents related to the provenance of the book. Physical characteristics include the height, width, and length of the book. Care should always be taken in measuring the book. A slight miscalculation may cause the box to be too small or too large to keep the book under the required pressure to prevent movement of the book within the box. Brown describes a very useful measuring kit that is quite easy to assemble. For more information about this kit it is recommended that her book be consulted. ${ }^{8}$ In addition to actual size, relative size is also important-is the book an oversized folio or is it simply of the thin pamphlet variety?

The librarian must also consider the book's present condition. Is the headcap damaged? Are the spine and covers attached to the textblock? Are any of the leaves of the textblock loose or detached? Is the paper of the textblock deteriorated in any way? Is foxing present? Are there signs that other vermin have attacked the book, and, if so, are they still active? It is important to understand the exact condition of the book at the time of inspection so the correct box may be chosen if comprehensive treatment is to be delayed. It is also a good idea to make notes of the condition and keep them with the book until treatment is complete.

All of these questions, when answered, provide a basis on which the librarian may choose a box. By ascertaining the exact condition and characteristics of the book, the librarian then begins to narrow down the choices, the end goal being a box that provides the best overall protection for the book.

But, from what boxes does the librarian have to choose? Permanent designs usually fall into one of four basic categories: (1) the slip case; (2) pull-off cases; (3) double-tray designs; and, (4) portfolios. ${ }^{9}$ 


\section{Slip Cases}

Slip cases (also known by many other names: slide cases, slip-in cases, open-back cases, or slide boxes to name a few), are perhaps the most common kind of book box used to store library materials. ${ }^{10}$ Many publishers sell their books in slip cases, but libraries merely discard them as unnecessary and too cumbersome for their patrons.

A simple slip case is "a box that has a front [i.e. upper] and back [i.e. lower] cover, is closed at head, tail, and fore-edge, and is open at the spine" (see Figure 1). "Each box should be custom made for the book and linings should be of soft flannel or acid free paper. ${ }^{12}$ The book should fit snugly within the case without slipping out or having to be removed by tugging at the spine. If the case is too tight, the edges of the book will be damaged and the covers abraded each time the book is removed; if the case is too loose, the volume may fall out of its own accord. ${ }^{13}$

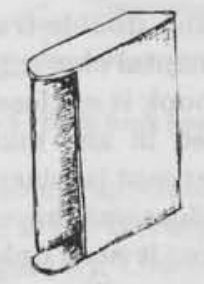

Figure 1. Slip case.

Several features may be added to the slip case that will significantly improve its effectiveness. First, the head and tail walls nearest the spine edge may be rounded preventing dust and other particulate matter from getting into the book. ${ }^{14}$ These rounded edges also prevent the user from removing the book by tugging at the headcap.

Second, a ribbon-pull may be added which aids in removing the book without damaging the spine. It should be attached to either the upper or lower cover wall of the slip case near the spine edge. One disadvantage of the ribbon-pull is that after many uses, the binding may begin to show signs of wear at the point the ribbon comes in direct contact with the book. More often though, the ribbon-pulls fray, then break.

A third addition are thumb holds. These semi-circular cuts in the upper and lower covers of the slip case allow the user to remove the book by pulling gently on the sides of the book rather than the spine or headcap. This is much preferred to the ribbon-pull, but the decision of which feature to use depends on how much the book is to be used and how elaborately the slip case will be decorated.

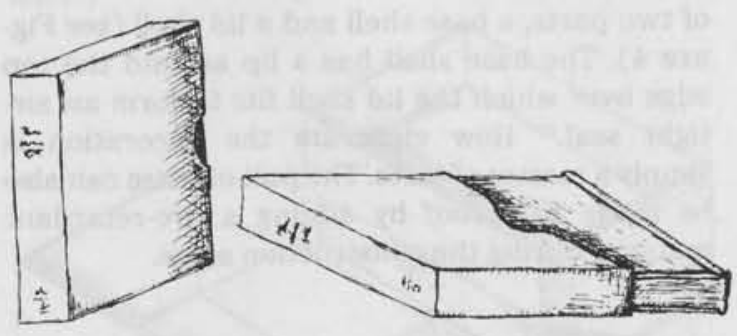

Figure 2. The reversed slip case (2 views).

Fourth, a wrapper, or chemise may be added. This protects all sides of the book from the environment (i.e. light, dust and dirt), and considerably reduces abrasion when inserting or removing the book from the slip case. The chemise is usually made of a type of book cloth and may be hidden from view by simply marking the fore-edge side of the slip case with the appropriate information (i.e. author, title, and call number), and shelving the spine edge of the case toward the back of the shelf. Some slip cases are designed this way on purpose and are known as reversed slip cases (see Figure 2). ${ }^{15}$ The only difference is that the spine is closed and the fore-edge side open, and the book is inserted from the open fore-edge side. The choice of which to use becomes simply a matter of preference. Although not a dust proof case, the open side of the box is designed to face the back of the shelf, which is better protected from the environment.

Slip cases can also be made for the purpose of keeping all volumes of a multi-volume work together (see Figure 3). The slip case is the only design where this is feasible. It is quite simple: one builds a slip case for each individual volume, then a slip case to fit around all of the volumes in the set and their cases.

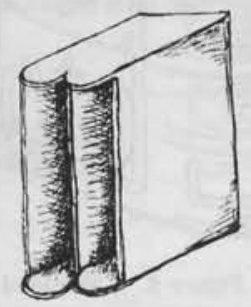

Figure 3. Slip case for a multi-volume set. 


\section{Pull-Off Cases}

A second category of boxes are moulded, telescopic, or pull-off cases. A pull-off case consists of two parts, a base shell and a lid shell (see Figure 4). The base shell has a lip around the top edge over which the lid shell fits to form an airtight seal. ${ }^{16}$ How elaborate the decoration is simply a matter of taste. The pull-off case can also be made fire-proof by adding a fire-retardant material during the construction stage.
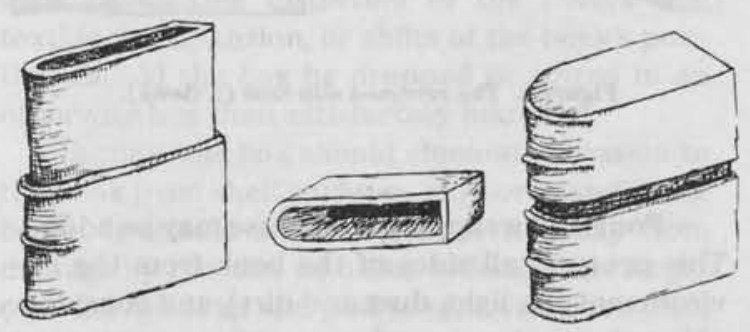

Figure 4. The pull-off case (2 views).

As with slip cases, the removal of a book involves either a pulling or shaking motion, a process that increases the possibility of damage. ${ }^{17}$ The pulling or shaking motion can cause the binding to be abraded (the main problem with pull-off cases), as the ideal fit should be a snug one. As with slip cases, if the book fits too tightly within the case, the covers will begin to show wear from the abrasion of the box against the binding after only a few uses. In addition, the book may be damaged by the patron while trying to remove it from, or replace it in the case. On the other hand, if the book fits too loosely, its movement within the box could damage it by causing bumped corners, abraded covers, etc. Again, as with all boxes, measurement during construction should be as precise as possible to insure a proper fit.

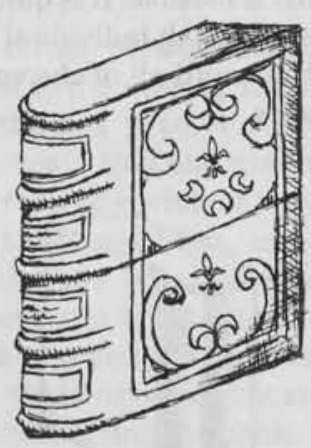

Figure 5. A Moulded case.

A moulded case (see Figure 5), sometimes falsely given the name Solander, is an elaborately decorated pull-off case (usually covered in morocco), similar to those described earlier. ${ }^{18}$ Harrison states that moulded cases have been misnamed by Americans as Solander cases. According to him, they have no relation. This confusion is quite evident throughout the literature. ${ }^{19}$ Discussion of this ambiguity is beyond the scope of this paper. Harrison is accepted at his word.

\section{In general, the more compli- cated the box design, the more expensive it is to make...}

\section{Double-Tray Formats}

A third category of boxes is the double-tray designs. These, like other types of boxes, have many common names-drop-back book box, falldown-back book box, and fore-edge grip box to name a few. Perhaps the most familiar name is the clamshell box.

All boxes of the double-tray variety should have these fundamental characteristics:

1. When the book is enclosed in the box, the book is not altered in any manner-nothing is done to the book except to place it in the box ${ }^{20}$;

2. The book does not have to be pulled or pushed into the box; it need only be laid gently in the container;

3. The box supports the book firmly, whether open for display or closed and placed on a shelf;

4. The box is both dust-proof and light-proof.

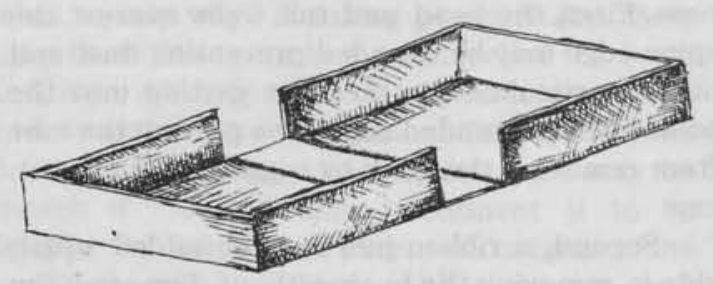

Figure 6. The basic double-tray design.

The basic double-tray box is simply a lid shell, a base shell, and a case (see Figure 6). All parts are usually covered in cloth or buckram. Each shell consists of a base, head, tail, and fore-edge walls. When the box is closed, the spine wall of the case functions as the support for the spine of the book. The lid shell then fits completely over the base shell keeping out light and particulate matter. String ties and buttons may be used to keep the box closed. Brown describes in detail numerous double-tray designs developed at the Library of Congress. To avoid repetition, only the design 
characteristics of these boxes as well as their uses will be discussed.

One variation of the basic double-tray box is the drop-back box (see Figure 7). This box is stronger and more substantial than the basic design because the head, tail, and fore-edge walls require the use of two thicknesses of binders boards instead of the single thickness called for in the basic box. Because of the way the case is made, the spine wall needs only a single thickness of binders boards. Unfortunately, the spine of the book is left totally unsupported when open as the spine wall has dropped-backed perpendicular to the spine of the book. The spine wall is necessary for books that are badly deteriorated so as to lessen the stress on the spine.

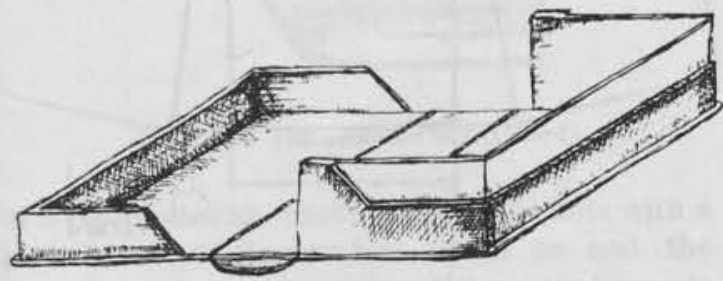

Figure 7. Drop back book box.

Another double-tray design, and one described by Brown, is the Library of Congress' rare book box (see Figure 8). This box is perhaps the best suited for storage of rare, or badly deteriorated books, be they made of paper, leather, or vellum materials. The difference between this box and other double-tray boxes is the addition of a fixed spine wall with an angled opening as part of the base shell. The added wall gives support to the spine of the book whether the box is open or closed. The angled opening allows the book to be removed from the box with ease and without damage. With the additional spine wall functioning as a brace for the other three walls of the base shell, the box is stronger than either the basic design or the drop-back box.

Double tray boxes can be modified to house a portfolio, either smaller or larger than the book, ${ }^{21}$ for the purpose of storing material related to the book, such as pieces of the original binding, articles, reviews, or other items related to the prov-

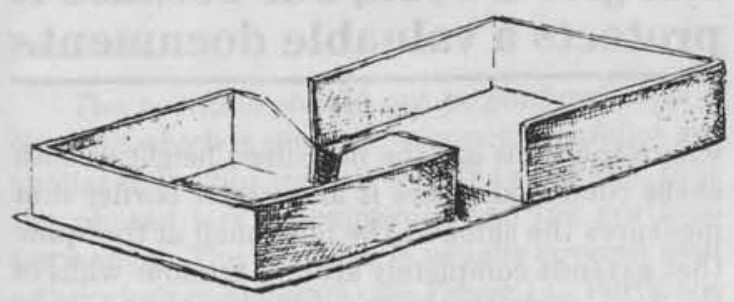

Figure 8. The standard rare book box. enance (see Figure 9). (The portfolio can also be used as a separate box and will be discussed later.)

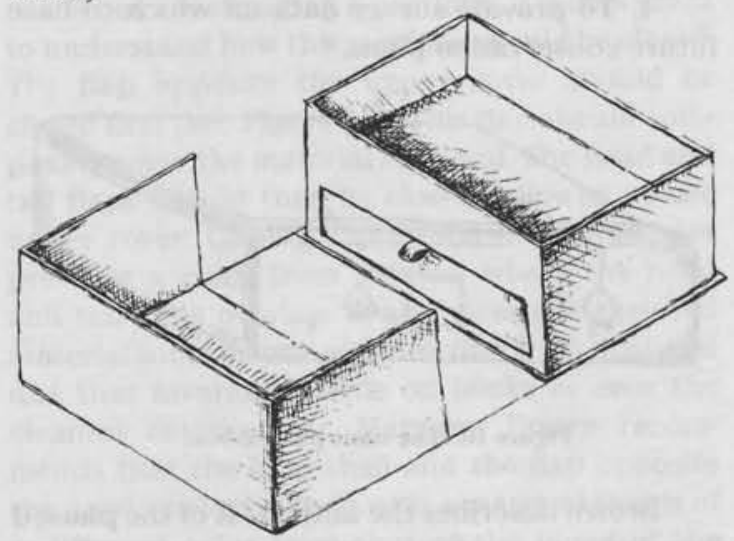

Figure 9. Standard Rare book box with portfolio.

With the addition of the portfolio, the book rests on an elevated shelf that is part of the base shell. Below the shelf, surrounded on three sides, is the portfolio. The slot usually has a ribbon-pull attached to aid in removal. When closed, the lid shell fits completely over the base shell enclosing both book and portfolio.

For the purpose of phased preservation, the LC preservation laboratory developed the phased box which is a kind of double tray box (see Figure 10). The phased box was designed to incorporate the following requirements:

1. To hold each volume and any detached pieces together.

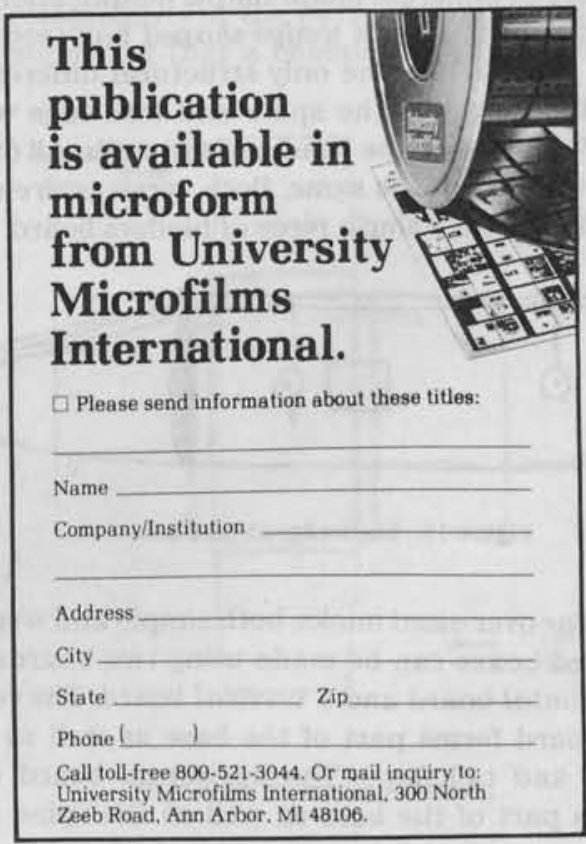


2. To prevent further distortion of hygroscopic materials.

3. To prevent further mechanical damage.

4. To provide survey data on which to base future conservation plans. ${ }^{22}$

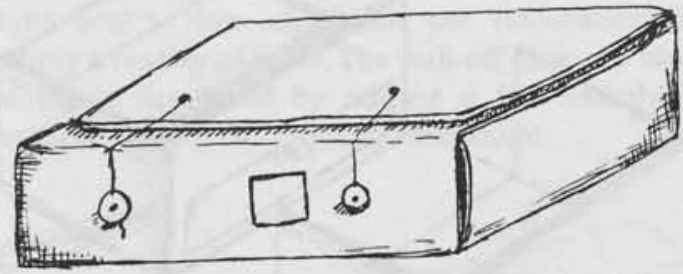

Figure 10. The basic phased box.

Brown describes the initial test of the phased box concept and its ultimate success. Those interested should consult her book.

A phased box is usually made from a single piece of acid-free binders board. It is folded, creased, and cut to form a base, four walls, and four flaps. All the flaps, with the exception of the tail flap, should be long enough, when folded, to cover the entire book. The tail flap should measure approximately one-third of the length of the book measured from head to tail. Thread ties and plastic buttons should be attached to the exterior of the box to keep it closed and the contents under firm, but even, pressure to prevent any movement within the box.

The simple phased box assumes that the spine and fore-edge width are the same. For books where these measurements differed, the Library of Congress made simple modifications to the design to form a wedge-shaped box (see Figures 11 and 12). The only structural differences are the height of the spine and fore-edge walls and the angle on the head and tail walls. All other aspects remain the same. Both versions are constructed from a single piece of binders board.

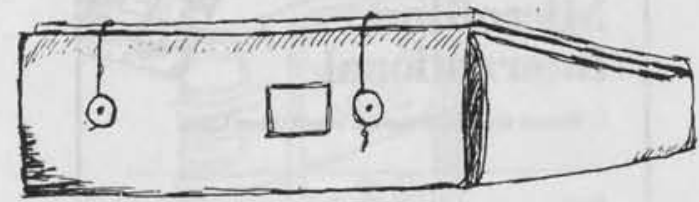

Figure 11. The wedge-shaped box.

For over-sized books, both simple and wedgeshaped boxes can be made using two boards-a horizontal board and a vertical board. The vertical board forms part of the base as well as the head and tail flaps. The horizontal board also forms part of the base as well as the spine and fore-edge flaps. After the boards have been creased and folded, forming the walls and flaps, they are laid perpendicular to each other, horizontal on top of vertical, and then attached to each other using the recommended adhesive. This forms the base of the phased box. The ties and buttons are then added to the exterior of the vertical board.

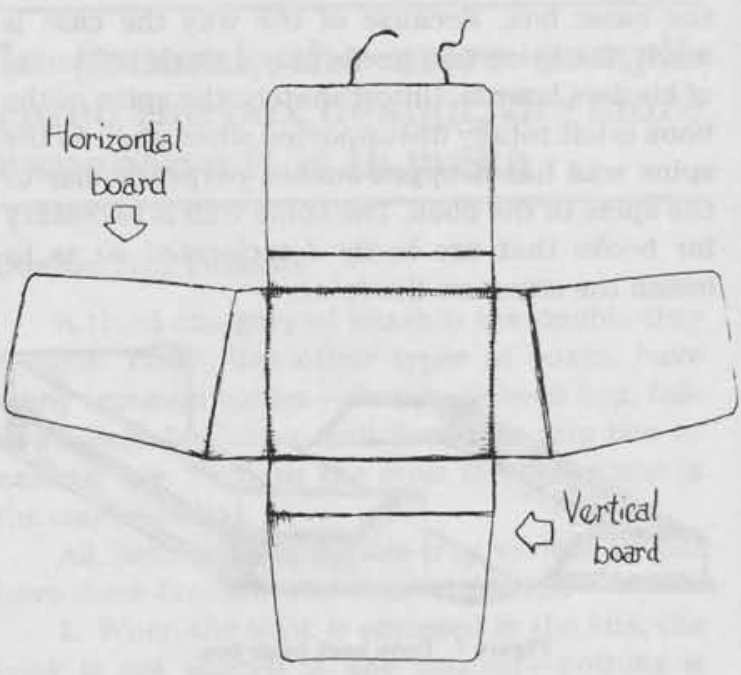

Figure 12. The wedge-shaped box (open).

Perhaps the oldest and most distinguished of the double-tray designs is the Solander box. This box was invented by Daniel Charles Solander for the purpose of preserving botanical specimens, but was later adapted for the storage of books. ${ }^{23}$ The Solander box is a carefully made box with a lid shell hinged at the spine (see Figure 13). When the box is closed the shells form a tight seal at the joint, head, tail, and fore-edge. The height of the lid shell should be approximately half of the height of the base shell measured at the spine of the book. The head and tail walls of the base shell are the same height except at the spine edge

The box is important not because of the enhancement it can give a book, but because it protects a valuable document.

where the walls are the measured height of both shells combined. There is an interior border that measures the same as the base shell at the spine that extends completely around the four walls of the base shell creating an air-tight and water- 
tight seal when the box is closed. Solanders are usually covered in full morocco with well designed panels lined in gold. The foundation is in wood with frames of pine wood with top and base cabinet made. ${ }^{24}$

A simplified solander, called a print box, can be used where the book's use is minimal. These solanders are cheaper, they retain efficient function, and are reasonably durable. These are made

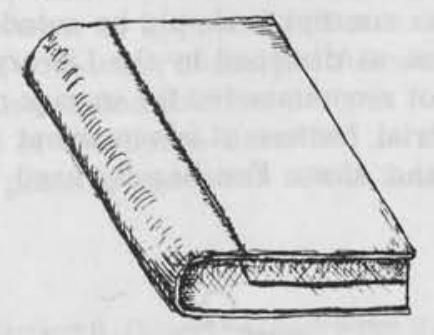

Figure 13. The Solander box (closed).

of 3-plywood with machine dovetail joints with a pine frame. If designed to stand on end, the solander will require catches. Fillets may be made of mill board. They should also be lined with a non-abrasive material. ${ }^{25}$ Either of these Solanders are well suited for storing most materials, from loose plates and pamphlets to rare books. ${ }^{26}$ Vellum materials are particularly well protected because they remain under enough pressure when the box is closed to keep them from warping. And because of the stable environment that can be maintained within the Solander, the books are protected from the environment.

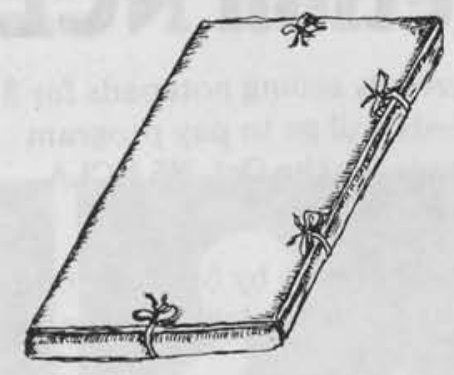

Figure 14. Portfolio (closed).

\section{Portfolios}

The portfolio should not be confused with a chemise which is simply a wrapper. Portfolios are similar to the phased box with the exception that the phased box is temporary and the portfolio permanent. The portfolio is usually covered with either cloth or buckram (see Figure 14). Portfolios are also lined with non-abrasive materials to protect the enclosed material from damage. Ties are added to the exterior to keep it closed.

When constructing a portfolio, it is important to understand how the portfolio should be closed. The flap opposite the upper cover should be closed first (see Figure 15). This flap should completely cover the material enclosed. The head and tail flaps should then be closed followed by the upper cover. Closing a portfolio in this manner prevents a ridge from forming where the head and tail flaps overlap. It also gives the enclosed material some degree of protection from dust and dirt that invariably settle on books in even the cleanest environment. Margaret Brown recommends that the base shell and the flap opposite the upper cover be lined with a material that is of a different color from that of the lining of the other three flaps. ${ }^{27}$ This makes it easy to know which flap should be closed first.

\section{Which Box To Use?}

Of the four categories of book boxes, each has its advantages and disadvantages. Slip cases, the most commonly used box, are the least expensive to make of the permanent designs. Any commercial binder should be able to make them for only a few dollars. Slip cases are best suited for the storage of cloth bound books that are in good condition, but may also be used to store pamphlets and unbound periodicals. ${ }^{28}$ They are not recommended for storing leather or vellum bindings because without sufficient protection for the spine, it may dry out and become brittle and in time deteriorate completely. For the purpose of preservation, it is important that a chemise be used with the

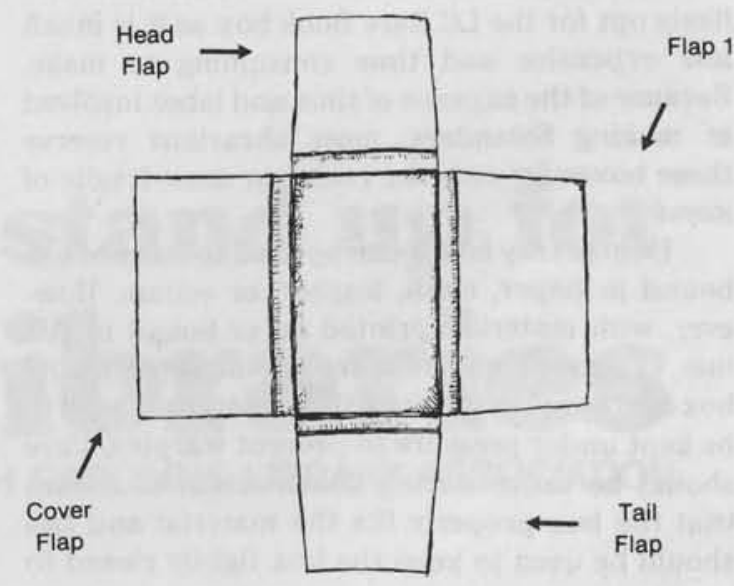

Figure 15. Portfolio (opened). 
slip case to help prevent various kinds of mechanical and environmental damage. If no chemise is used, protection will be significantly reduced because at least one edge of the book is exposed to the environment at all times.

Pull-off cases seem to be the least useful as preservation containers unless the material is seldom used. The pull-off case does protect its contents from the environment, which is crucial to a good box, but only small books or pamphlets should be stored in them. They should never be used for the storage of large books or other heavy oversized material as the box would be too cumbersome for the patron to use.

Although the slip case and the pull-off case do provide adequate protection for books, abrasion can occur when books are removed from these boxes.

Book boxes have been around for quite some time. They have been, and probably still are, most often thought of as something to enhance the appearance of prestigious books, not as something that will help preserve them.

Double-tray boxes are the best suited for the protection of books. Inexpensive designs such as the basic clam-shell box, may be used to store books that are in excellent condition, while the Library of Congress Rare Book box, or a Solander box, may be used to store beoks in original boards that are in poor condition. Most librarians will likely opt for the LC Rare Book box as it is much less expensive and time consuming to make. Because of the expense of time and labor involved in making Solanders, most librarians reserve these boxes for only the rarest or most fragile of items.

Double tray boxes can be used to store books bound in paper, cloth, leather, or vellum. However, with materials printed on or bound in vellum, caution should be exercised in preparing the box for the material, since these materials need to be kept under pressure to prevent warping. Care should be taken during construction to assure that the box properly fits the material and ties should be used to keep the box tightly closed to insure a constant, even pressure over the entire surface of the book.

A key advantage of the double tray boxes is their capacity for the addition of a multipurpose portfolio that may be used to store material related to the book.

All of the double tray boxes described are dust-proof and provide a stable environment for the book, while allowing no movement of the book while in the box.

If librarians should decide to employ the phased box concept it should be noted that the phased box, as designed by the Library of Congress, is not recommended for storage of heavily used material, because it is somewhat awkward to open and close. For heavily used books, a

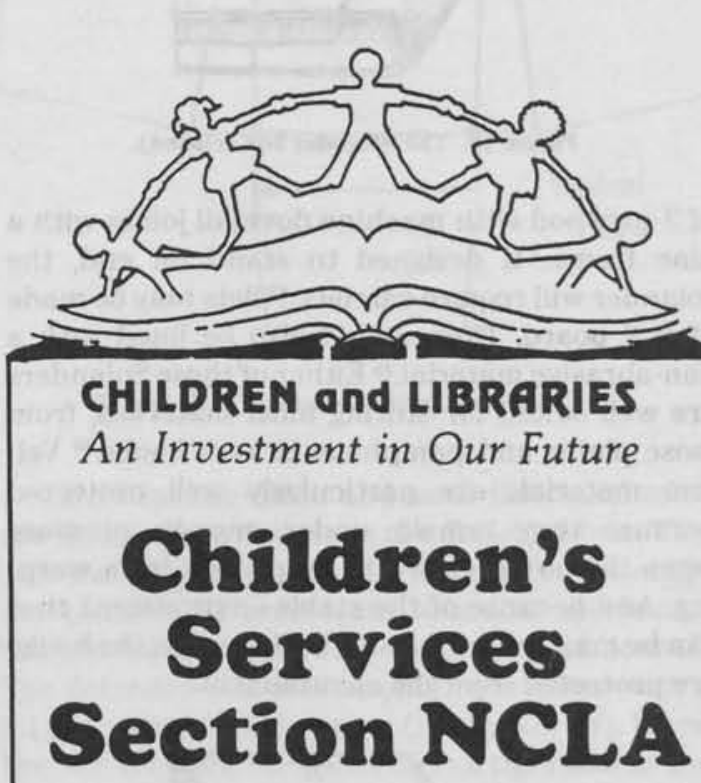

Is currently selling notepads for $\$ 1.00$. Proceeds will go to pay program expenses for the Oct. '85 NCLA Conference.

The pads are $8^{1 / 2}$ by $5 \frac{1}{1 / 2}$, have 50 pages each, and are available in blue, gold, and pink.
Order from: Rebecca Taylor
New Hanover Co. Public Library
201 Chestnut St.
Wilmington, NC 28401

$\$ 1.00$ each +50 \& postage \& handling 
library should consider immediate conservation treatment rather than phased boxing, as heavy use of an already badly deteriorated book can only cause further damage. Although phased boxes are quite durable, they should not be thought of as a permanent solution for the problem of book preservation.

Finally, portfolios provide the best protection for large prints, plates, etc., for which the other boxes were not designed. As these materials need to be flat, with a portfolio, they may be stored vertically with no appreciable harm. And as we have seen with other boxes, portfolios can also be used as an addition to other designs.

Most of the boxes described in this paper, with the possible exception of the Solander box, can be made by a person on the library staff and all should be available from a commercial bindery. In general, the more complicated the box design, the more expensive it is to make, primarily because it is very labor-intensive work. If a less elaborate box will accomplish the same purpose as a more elaborate one, libraries are more likely to use the simpler box while collectors may opt for the more elaborate design.

Regardless of the type of box used, it is important to select a design that will best protect the material to be contained in it. The box is important not only because of the enhancement it can give a book, but because it protects a valuable document. And it is this valuable document that is, in the end, the most important.

\section{References}

1. Brown, Margaret R., Design and Construction of Boxes for the Protection of Rare Books (Washington, D.C.: Library of Congress Preservation Office, 1982), xix-xxv.

2. Ibid., xxii.

3. Ibid, $x x$.

4. Ibid, xv.

5. Cunha, George Daniel Martin, Conservation of Library Materials, 2nd ed. (Metuchen, N.J:: Scarecrow Press, 1971), 103.

6. Carter, John, $A B C$ for Book Collectors, 5th ed. (London: Rupert Hart-Davis, 1972), 56.

7. See note 4 above.

8. Brown, Design and Construction of Book Boxes for the Protection of Rare Books, xxvi-xxvii.

9. Carter, $A B C$ for Book Collectors, 55.

10. Cunha, Conservation of Library Materials, 319.

11. Young, Laura S., Bookbinding and conservation by hand: $A$ working guide (New York: R.R. Bowker, 1981), 215.

12. Rebsamen, Werner, "Binding," Library Trends 30 (Fall 1981): 229.

13. See note 9 above.

14. Peet, Nicola, "Boxes and Slip-cases," The Private Library 5 (Winter 1982): 204.
15. Johnson, Arthur W., Manual of Bookbinding (New York: Charles Scribner's Sons, 1978), 184.

16. See note 6 above.

17. Wilson, Robert A., Modern Book Collecting (New York: Alfred A. Knopf, 1980), 184.

18. See note 6 above.

19. Harrison, T., Fragments of Bookbinding Technique (London: London School of Printing, 1950), 29.

20. Spawn, Willman, "Physical Care of Books and Manuscripts," in Jean Peters, ed. Book Collecting: A Modern Guide (New York: R.R. Bowker, 1977), 141.

21. Brown, Design and Construction of Boxes for the Protection of Rare Books, 95.

22. Ibid., 2.

23. Glaister, Geoffrey Ashall, Glaister's Glossary of the Book, 2nd ed. (Berkeley: University of California Press, 1979), 451.

24. Harrison, Fragments of Bookbinding Technique, 39.

25. Ibid., 40 .

26. See note 23 above.

27. Brown, Design and Construction of Book Boxes for the Protection of Rare Books, 37.

28. Young, Bookbinding and Conservation by Hand: A Modern Guide, 215. 